\title{
Alta prevalencia de enzimas modificadoras de aminoglucósidos (EMAs) en aislados clínicos de Klebsiella pneumoniae (KPN) productores de $\beta$-lactamasas de espectro extendido (BLEE)
}

\author{
David Ortega ${ }^{1}$, Iliana Alcocer ${ }^{1} \&$ Jeannete Zurita $^{2}$ \\ 'Laboratorio de Microbiología, Escuela de Ciencias Biológicas, PUCE, Quito, Ecuador. \\ iralcocer@puce.edu.ec \\ ${ }^{2}$ Departamento de Microbiología, Zurita\&Zurita Laboratorios, Quito, Ecuador
}

RESUMEN: Klebsiella pneumoniae productora de $\beta$-lactamasas de espectro extendido (BLEE) es un agente microbiano involucrado en infecciones graves en ambientes hospitalarios con altas tasas de mortalidad y morbilidad, debido a las escasas alternativas terapéuticas disponibles y a su rápida adquisición de genes de resistencia a diversos antibióticos. El objetivo fue determinar la prevalencia de genes de enzimas modificadoras de aminoglucósidos (EMAs) en Klebsiella pneumoniae productora de $\beta$-lactamasas de espectro extendido. Cuarenta y dos aislados de Klebsiella pneumoniae fueron incluidos en este estudio y provienen de varios centros hospitalarios de Quito, colectados de Mayo de 2005 a Agosto de 2008. Se confirmó su identificación fenotípica, genotípica, la producción de BLEE y perfil de resistencia a 30 antibióticos por métodos estándares. La detección de los genes EMAs se realizó por PCR utilizando iniciadores de identificación de los genes ant(2")-Ia, $a a c\left(6^{\prime}\right)-I b$ y $a a c(3)-I I a$. Los aislados mostraron una mayor producción de cefotaximasas sobre ceftazidimasas. Se registró alta resistencia a $\beta$-lactámicos, mientras que, no se registró resistencia a polimixina $\mathrm{B}$, colistina, tigeciclina. Fue evidente la alta prevalencia de genes EMAs en la población estudiada.

PALABRAS CLAVE: $\beta$-lactamasas de espectro extendido, enzimas modificadoras de aminoglucósidos, Klebsiella pneumoniae, multiresistencia.

High prevalence of aminoglycoside modifying enzimes (AMEs) in clinical isolates of Klebsiella pneumoniae (KPN) producing extended spectrum $\beta$-lactamases (ESBL)

ABSTRACT: Klebsiella pneumoniae producing extended spectrum $\beta$-lactamases (ESBL) is a microbial agent involved in serious infections in hospital environments with high rates of mortality and morbidity due to the limited therapeutic options available and its rapid acquisition of resistance genes to various antibiotics. The objective was to determine the prevalence of genes for aminoglycoside modifying enzymes 
(AMEs) in Klebsiella pneumoniae producing extended spectrum $\beta$-lactamases. Fortytwo Klebsiella pneumoniae isolates were included in this study and from several hospitals in Quito, collected from May 2005 to August 2008. Identification was confirmed phenotypic, genotypic, production of ESBL and resistance profile to 30 antibiotics by standard methods. The detection of EMAs genes was performed by PCR using primers for the identification of genes ant (2")-Ia, aac (6')-Ib and aac(3)-IIa. Isolates showed an increased production of cefotaximasas on ceftazidimases. There was high resistance to $\beta$-lactamics, whereas there was no resistance to polymyxin $\mathrm{B}$, colistin, tigecycline. It was clear the high prevalence of EMAs genes in the population studied.

KEY WORDS: Aminoglycoside modifying enzymes, extended spectrum $\beta$-lactamases, Klebsiella pneumoniae, multiresistance.

INTRODUCCIÓN.- Klebsiella pneumoniae (KPN) (Schroeter, 1886 y Trevisan, 1887) es un bacilo Gram negativo cuyo nicho ecológico es el intestino de homeotermos. En el ser humano, esta bacteria está implicada en infecciones del tracto respiratorio (1), tracto urinario (2), sistema nervioso, osteoarticular (3) e incluso puede alcanzar el sistema circulatorio ocasionando cuadros severos de sepsis (4).

KPN presenta resistencia intrínseca a ampicilina y ticarcilina debido a la presencia del gen que codifica la enzima SHV-1 y ha adquirido resistencia para casi todos los antibióticos utilizados en el arsenal terapéutico (5). A partir de los años 80 empezaron a circular cepas con resistencia a las cefalosporinas de tercera generación como ceftazidima, cefotaxima y ceftriaxona, y de cuarta generación como cefepima, originando un grave problema para el tratamiento de pacientes con infecciones producidas por estas cepas. La resistencia en KPN a todas las cefalosporinas es generada por $\beta$ lactamasas de espectro extendido, conocidas como BLEE (6). Dejando como única alternativa de tratamiento el grupo de los carbapenemes y cefamicinas. No obstante, hace aproximadamente dos años empezaron a circular KPN resistentes a estos dos grupos de antimicrobianos: carbapenemes y cefamicinas; con lo que se redujeron, aún más, las alternativas de tratamiento (7).

Las $\beta$-lactamasas de espectro extendido (BLEE) son enzimas bacterianas capaces de inactivar antibióticos $\beta$-lactámicos por hidrólisis, convirtiéndolos en compuestos inefectivos para el tratamiento. Los genes que codifican enzimas tipo BLEE se encuentran, usualmente, en elementos génicos de fácil diseminación, como es el caso de plásmidos e integrones. Esto sumado a su frecuente relación con otros determinantes de resistencia a antibióticos de otras familias (quinolonas y aminoglucósidos), convierten a los aislados de este tipo en importantes problemas terapéuticos a nivel hospitalario (8).

Las BLEE son un problema de salud pública con proporciones alarmantes de prevalencia en Latinoamérica, alcanzando tasas preocupantes en Colombia, Guatemala, Perú, México, Venezuela, Ecuador, Argentina, Chile, Panamá y Brasil. 
La utilización de cefalosporinas de tercera generación ejerce una presión importante en las bacterias Gram negativas (9). El $50 \%$ de las infecciones hospitalarias son tratadas con antibióticos $\beta$-lactámicos y cerca del $70 \%$ de las infecciones de los pacientes extrahospitalarios son tratadas con cefalosporinas, lo cual sugiere la existencia de una fuerte presión selectiva en esta zona de América (10 y 11).

A pesar de que los aminoglucósidos han sido poco utilizados, como alternativa en el tratamiento de infecciones producidas por KPN productoras de BLEE, ya se han registrado cepas resistentes a este grupo de antibióticos. Uno de los mecanismos de resistencia a los aminoglucósidos es la presencia de genes productores de enzimas modificadoras de aminoglucósidos conocidas como EMAs.

\section{OBJeTivos.-}

\section{GENERAL:}

Determinar la prevalencia de genes de enzimas modificadoras de aminoglucósidos en Klebsiella pneumoniae productora de $\beta$-lactamasas de espectro extendido.

\section{ESPECÍFICOS:}

- Confirmar la previa identificación bioquímica de Klebsiella pneumoniae mediante la reacción en cadena de la Polimerasa (PCR) por amplificación de regiones espaciadoras intergénicas (ISRs).
- Confirmar la producción de $\beta$-lactamasas de espectro extendido (BLEE) a nivel fenotípico.

- Determinar el perfil de resistencia a antibióticos "in vitro".

- Detectar la presencia de genes productores de enzimas modificadoras de aminoglucósidos (EMAs) mediante PCR.

\section{MATERIALES Y MÉTODOS.-}

Aislamientos bacterianos.- Los aislados de KPN provinieron de la colección del Departamento de Microbiología de Zurita\&Zurita Laboratorios. Los aislamientos provienen de varios centros hospitalarios de la ciudad de Quito, Ecuador. Fueron colectados durante el período de Mayo de 2005 a Agosto de 2008. Las muestras provienen de procesos infecciosos documentados. Se tomó de manera aleatoria un aislamiento por paciente. Cuarenta y dos aislamientos confirmados como productores de BLEE, fueron incluidos en este estudio (Tabla 1).

\section{Confirmación fenotípica y genotípica} de Klebsiella pneumoniae.- Klebsiella pneumoniae de acuerdo a sus reacciones bioquímicas se identifica como un bacilo no mótil, es fermentador de lactosa, productor de ornitina descarboxilasa, no productor de triptofanasas y que presenta una fermentación butilén-glicólica. Para evidenciar este perfil se realizaron las pruebas bioquímicas estándares: Agar con triple azúcar y hierro (TSI), Motilidad, Indol, Ornitina (MIO) y Rojo de metilo (RM)/Vogues-Proskauer (VP). 
La confirmación molecular de los aislados se realizó mediante la técnica de ribotipage por PCR, empleando los iniciadores descritos por Kostman et al. (12), rtF 5'TTGTACACACCGCCCGTCA 3' y rtR 5'GGTACCTTAGATGTTTCAGTTC 3', y las condiciones descritas por Lopes et al. (13) con ligeras modificaciones.

El templado fue preparado mediante kit de extracción de ADN genómico (PROMEGA, A1120). La reacción se preparó en un volumen final de $25 \mu \mathrm{l}$ conteniendo $1 \mathrm{U}$ de Taq polimerasa (PROMEGA), $0,16 \mathrm{mM}$ de cada dNTP, $2 \mathrm{mM}$ de $\mathrm{MgCl} 2,20 \mathrm{pmol}$ de cada iniciador y $1 \mu \mathrm{l}$ de ADN templado en tampón para PCR 1X. La amplificación se realizó en un termociclador GeneAmp PCR system 9700 (Perkin Elmer). El programa de PCR consistió en 25 ciclos de 94 ${ }^{\circ} \mathrm{C}$ por 30 s, $57{ }^{\circ} \mathrm{C}$ por 30 s y $72{ }^{\circ} \mathrm{C}$ por 50 s, seguido de un paso de extensión final de $72{ }^{\circ} \mathrm{C}$ por $10 \mathrm{~min}$.

Los productos de PCR se sometieron a electroforesis en geles de agarosa al $2 \%$ a $125 \mathrm{~V}$ por 70 min en tampón $44,5 \mathrm{mM}$ tris$\mathrm{HCl}, 44,5 \mathrm{mM}$ ácido bórico, 1,5mM EDTA (TBE). Se empleó como marcador molecular ADN de 100pb (Invitrogen). Los geles fueron teñidos empleando syber gold $10.000 x$ en DMSO (Invitrogen). Los productos de amplificación se analizaron en Safe Imager (Invitrogen) por examen visual considerando todas las bandas visibles, independientemente de su intensidad.

Confirmación de Klebsiella pneumoniae productora de $\beta$-lactamasas de espectro extendido (BLEE).- Para la confirmación fenotípica de producción de BLEE se empleó el método de difusión en disco recomendado por Kirby-Bauer (14) y el método de aproximación de doble disco siguiendo las recomendaciones del "Clinical and Laboratory Standards Institute", CLSI (15).

Se colocaron discos de ceftazidima (CAZ), 30 $\mu \mathrm{g}$; ceftazidima/clavulanato (CZC), $40 \mu \mathrm{g}$; cefotaxima (CTX), 30 $\mu \mathrm{g}$ y cefotaxima/clavulanato $40 \mu \mathrm{g}$, adicionalmente se empleó un disco de cefoxitin (FOX) de manera equidistante. Los aislados que presentaron un aumento en $\geq 5 \mathrm{~mm}$ en el halo de inhibición de la cefalosporina de tercera generación (CG3) en combinación con clavulanato, se consideraron como positivos para la producción de BLEE. El carácter de resistente para cefoxitin se interpretó como posible producción de $\beta$-lactamasas de tipo AmpC (16).

Pruebas de susceptibilidad.- Para el análisis de la susceptibilidad a antimicrobianos se empleó el método de difusión en disco (14) siguiendo las recomendaciones y criterios de interpretación propuestos por el CLSI (15). Se determinó la susceptibilidad a 30 antibióticos: Ampicilina (AM), $\quad 10 \mu \mathrm{g} ; \quad$ ampicilina/sulbactam (SAM), 10/10 $\mu \mathrm{g}$; amoxicilina/clavulanato (AMC), 20/10 $\mu \mathrm{g}$; piperacilina (PIP), $100 \mu \mathrm{g}$; piperacilina/tazobactam (PTZ), 100/10 $\mu \mathrm{g}$; aztreonam (ATM), 30 $\mu \mathrm{g}$; cefazolina (CZ), 30 $\mu \mathrm{g}$; cefalotina (KF), $30 \mu \mathrm{g}$; cefuroxima (CXM), 30 $\mu \mathrm{g}$; cefoxitina (FOX), 30 $\mu \mathrm{g}$; ceftazidima (CAZ), 30 $\mu \mathrm{g}$; cefotaxima (CTX), 30 $\mu \mathrm{g}$; cefepime (FEP), $30 \mu \mathrm{g}$; imipenem (IPM), $10 \mu \mathrm{g}$; meropenem (MEM), $10 \mu \mathrm{g}$; amikacina (AK), 30 $\mu \mathrm{g}$; gentamicina $(\mathrm{CN}), 10 \mu \mathrm{g}$; netilmicina (NET), $30 \mu \mathrm{g}$; tobramicina (NN), $10 \mu \mathrm{g}$; neomicina $(\mathrm{N}), 10 \mu \mathrm{g}$; kanamicina $(\mathrm{K})$, $30 \mu \mathrm{g}$; ciprofloxacina (CIP), $5 \mu \mathrm{g}$; cloranfe- 
nicol (C), 30 $\mu \mathrm{g}$; trimetoprim sulfametoxaso (SXT), 1,25/23,75 $\mu \mathrm{g}$; tetraciclina (TE), $10 \mu \mathrm{g}$; tigeciclina (TGC), $15 \mu \mathrm{g}$; fosfomicina (FF), $200 \mu \mathrm{g}$; colistina (CT), $10 \mu \mathrm{g}$; polimixina B (PB), 300 $\mu \mathrm{g}$; Nitrofurantoína (F), 300 $\mu$ g. (Bioanalys ${ }^{\circledR}$, Turkey). Los diámetros de los halos de inhibición obtenidos, en milímetros, definieron el carácter sensible o resistente del aislado según el CLSI (15).

Detección de genes EMAs.- La detección de genes productores de EMAs se realizó por PCR. Se investigaron tres de los genes más frecuentemente encontrados en enterobacterias (17).

Los iniciadores empleados para el gen ant(2")-Ia fueron aadB F 5'CGTCATGGAGGAGTTGGACT $3^{\prime}$ y $\quad$ aadB $\quad \mathrm{R}$ 5 CGCAAGACCTCAACCTTTTC 3' (18); para el gen $a a c\left(6^{\prime}\right)$-Ib se emplearon los iniciadores aac(6')-Ib F 5'TATGAGTGGCTAAATCGAT $3^{\prime}$ y aac(6')-Ib R 5'CCCGCTTTCTCGTAGCA 3' (19); y para el gen $a a c(3)$-IIa se usaron los iniciadores aacC2 F 5' CGCTAAACTCCGTTACC 3 ' y aacC2 R 5'TAGCACTGAGCAAAGCC 3' (20). Las condiciones de amplificación fueron las descritas por Díaz et al. (18).

El templado fue preparado mediante kit de extracción de ADN genómico (PROMEGA, A1120). La reacción se preparó en un volumen final de $30 \mu \mathrm{l}$, conteniendo $0,25 \mathrm{U}$ de $T a q$ polimerasa (PROMEA), 0,11 mM de cada dNTP, $2 \mathrm{mM}$ de $\mathrm{MgCl}_{2}, 0,04 \mu \mathrm{M}$ de cada iniciador y $1 \mu \mathrm{l}$ de ADN templado en tampón para PCR 1X. La amplificación se realizó en un termociclador GeneAmp PCR system 9700 (Perkin Elmer). El programa de PCR consistió en un ciclo inicial de $96{ }^{\circ} \mathrm{C}$ por 30 s, $55{ }^{\circ} \mathrm{C}$ por 1 min y $70{ }^{\circ} \mathrm{C}$ por $3 \mathrm{~min}$, seguido de 25 ciclos de $96^{\circ} \mathrm{C}$ por $15 \mathrm{~s}, 55^{\circ} \mathrm{C}$ por $30 \mathrm{~s}, 70{ }^{\circ} \mathrm{C}$ por 30 s y un paso de extensión final de $70{ }^{\circ} \mathrm{C}$ por $5 \mathrm{~min}$.

Los productos de PCR se sometieron a electroforesis con las mismas condiciones empleadas para el ribotipaje por PCR.

\section{RESULTADOS}

Se estudiaron 42 aislamientos de Klebsiella pneumoniae productores de BLEE. Los datos de las fuentes de aislamientos se encuentran en la Tabla 1. El $100 \%$ de los aislamientos fueron confirmados como Klebsiella pneumoniae, mediante análisis genotípico (Figura 1). El ribotipaje por PCR concordó con la identificación manual bioquímica, además la producción de BLEE fue corroborada de acuerdo a las norma CLSI (Figura 2).

Treinta y dos de los 42 aislamientos

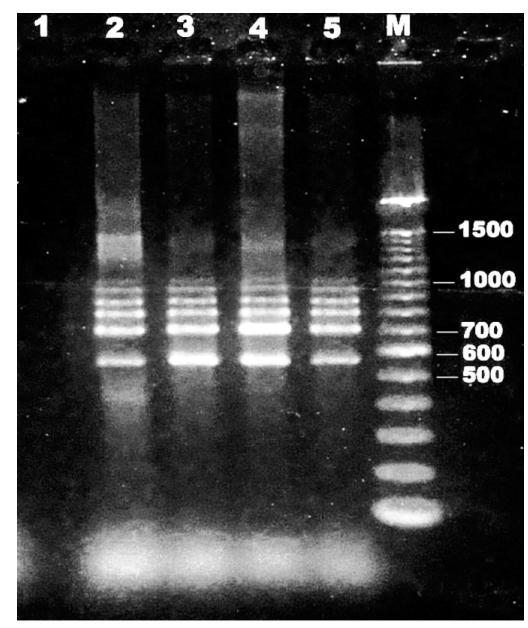

Figura 1.- Gel representativo de ribotipaje por reacción de la polimerasa. 1 - Control negativo agua; 2,3,4,5 - Patrones de bandas característicos de Klebsiella pneumoniae; $\mathrm{M}$ - Marcador molecular. 


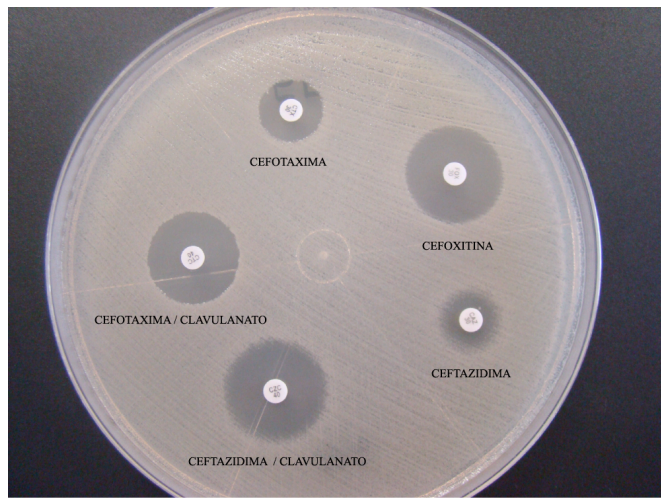

Figura 2.- Comprobación fenotípica de la producción de $\beta$-lactamasas de expectro extendido (BLEE). Aislado positivo para producción de cefotaximasas, ceftazidimasas y no productor de $\beta$-lactamasas tipo AmpC.

fueron productores concomitantemente de cefotaximasas y ceftazidimasas $(76,2 \%)$, seisde los aislados $(14,3 \%)$ presentaron únicamente el perfil de producción de cefotaximasas, y dos aislados $(4,8 \%)$ presentaron el perfil enzimático para ceftazidimasas. Finalmente, siete aislados $(4,8 \%)$ mostraron una reducción en el halo de inhibición para cefoxitina (FOX), lo que permite sospechar de la producción de enzimas $\beta$ lactamasas tipo AmpC (Figura 3).

En los 42 aislamientos de Klebsiella

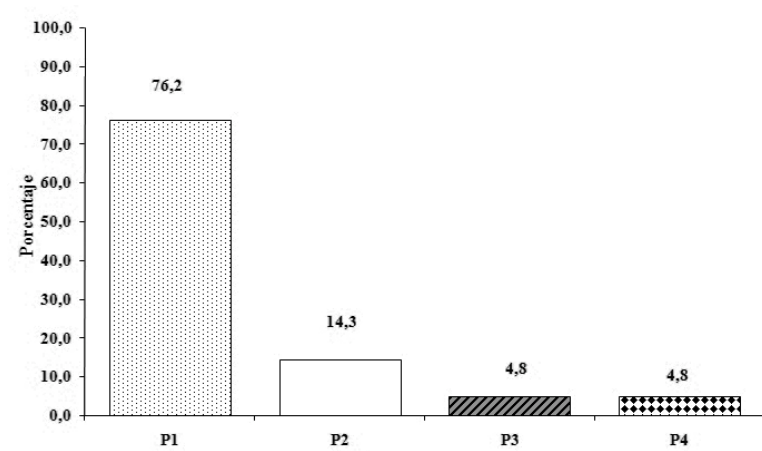

Figura 3.- Perfiles de producción de $\beta$-lactamasas de espectro extendido en aislados clínicos de Klebsiella pneumoniae. Pl - Productores de ceftazidimasas y cefotaximasas; P2 - Productores de cafotaximasas; P3 - Productores de ceftazidimasas; P4 - Posibles productores de $\beta$-lactamasas tipo AmpC. pneumoniae los perfiles de resistencia a los 30 antibióticos evaluados mostraron un alto porcentaje de resistencia a $\beta$-lactámicos, registrándose un $100 \%$ de resistencia para ampicilina, piperacilina, cefazolina, cefalotina, cefuroxima y cefotaxima; $95,2 \%$ de los aislados fueron resistentes a aztreonam; $88,1 \%$ fueron resistentes a ceftazidima y $69,0 \%$ a cefepime. Las combinaciones $\beta$ lactámicos/inhibidores de $\beta$-lactamasas mostraron porcentajes de resistencia de $83,3 \%, \quad 73,8 \%$ y $26,2 \%$ para amoxicilina/clavulanato, ampicilina/sulbactam y piperacilina/tazobactam, respectivamente. Los antibióticos $\beta$-lactámicos con los cuales se registró un menor porcentaje de aislados resistentes fueron los carbapenémicos, imipenem y meropenem, con $0,0 \%$ y cefoxitina, una cefamicina, con $16,7 \%$ de aislados resistentes.

En el grupo de los antibióticos aminoglucósidos fue registrado el mayor número de aislados resistentes para kanamicina con un $64,3 \%$, seguido de tobramicina con un $61,9 \%$. Gentamicina y netilmicina produjeron $52,4 \%$ y $50,0 \%$ de resistencia, respectivamente. Mientras que, neomicina mostró $11,9 \%$ y amikacina registró $7,1 \%$ de aislados resistentes. Ciprofloxacina, una quinolona, arrojó 69,0\% de aislados resistentes. Cloranfenicol mostró $47,6 \%$ de aislados resistentes, en tanto que la combinación trimetoprima/sulfametoxasole reveló un $40,5 \%$. Tetraciclina y tigeciclina arrojaron 57,1 y $0,0 \%$ de aislados resistentes. Los aislados mostraron $23,8 \%$ de 
resistencia a fosfomicina, $0 \%$ de resistencia a las polimixinas (colistina y polimixina B) y $50 \%$ de resistencia a nitrofurantoína (Figura 4).
Por otro lado, el gen aac(3)-IIa registró una reducción en la prevalencia con $60 \%$ en el 2005, 29,4\% en el 2006, 12,5\% en el 2007 y $0,0 \%$ en el 2008 (Figura 6). Finalmente el gen $a a c\left(6^{\prime}\right)-I b$ presentó una prevalencia

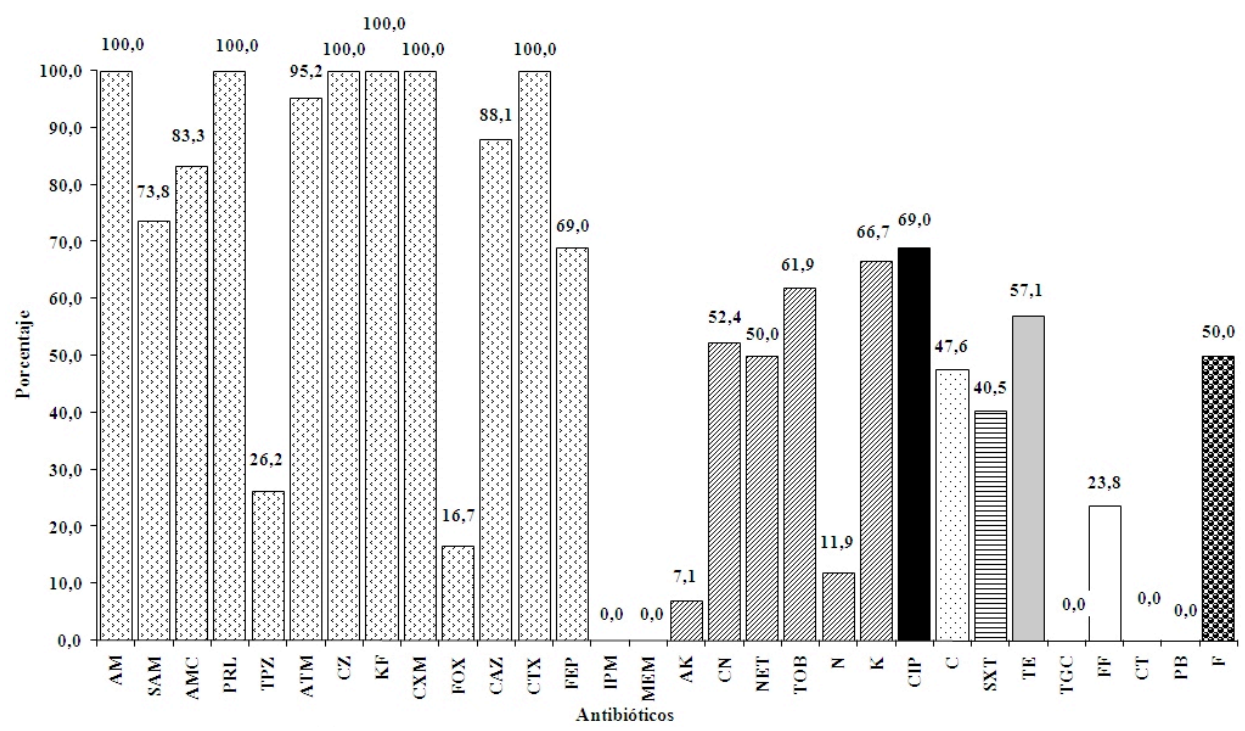

Figura 4.- Perfiles de resistencia a antibióticos de Klebsiella pneumoniae productoras de ß-lactamasas de espectro extendido. Antibióticos: AM - ampicilina; SAM - ampicilina / sulbactam; AMC - amoxicilina / clavulanato; PRL - piperacilina; TPZ - piperacilina / tazobactam; ATM - aztreonam; CZ - cefazolina; KF - cefalotina; CXM - cefuroxina; FOX - cefoxitina; CAZ - ceftazidima; CTX - cefotaxina; FEP - cefepina; IPM - imipenem; MEM - meropenem; AK - amikacina; CN - gentamicina; NET - netilmicina; TOB tobramicina; $\mathrm{N}$ - neomicina; $\mathrm{K}$ - kanamicina; CIP - ciprofloxacina; $\mathrm{C}$ - cloranfenicol; SXT - trimetroprina / sulfametoxasol; TE - tetraciclina; TGC - tigeciclina; FF - fosfomicina; CT - colistina; PB - polimixina $\mathrm{B} ; \mathrm{F}$ - nitrofurantoína.

Los genes $\operatorname{aac}(3)-I I a, a a c\left(6^{\prime}\right)-I b$ y $\operatorname{ant}(2 ")-I a$ fueron confirmados en los aislados a través de PCR (Figura 5) con amplicones de alrededor de $300 \mathrm{pb}, 400 \mathrm{pb}$ y $250 \mathrm{pb}$, respectivamente. El gen ant(2")-Ia registró un ligero aumento del año 2005 $(10 \%)$ al año $2006(29,4 \%)$ seguido de una disminución $(25,0 \%)$ en el 2007 , siendo que para el 2008 ningún aislado presentó este gen (Figura 6). regularmente alta en relación a los otros genes ( $\operatorname{aac}(3)$-IIa y ant(2")-Ia). Registrando un aumento de $80,0 \%$ a $94,1 \%$ de 2005 a 2006; en el año 2007 su prevalencia decreció a un 75,0\% y se incrementó ligeramente a un $85,7 \%$ en el año 2008 (Figura 6). Es importante resaltar para el 2008 el único gen presente en la población de estudio fue el gen $a a c\left(6^{\prime}\right)-I b$ con registro de 0,0 para los genes $a a c(3)-I I a$ y ant(2")-Ia. 


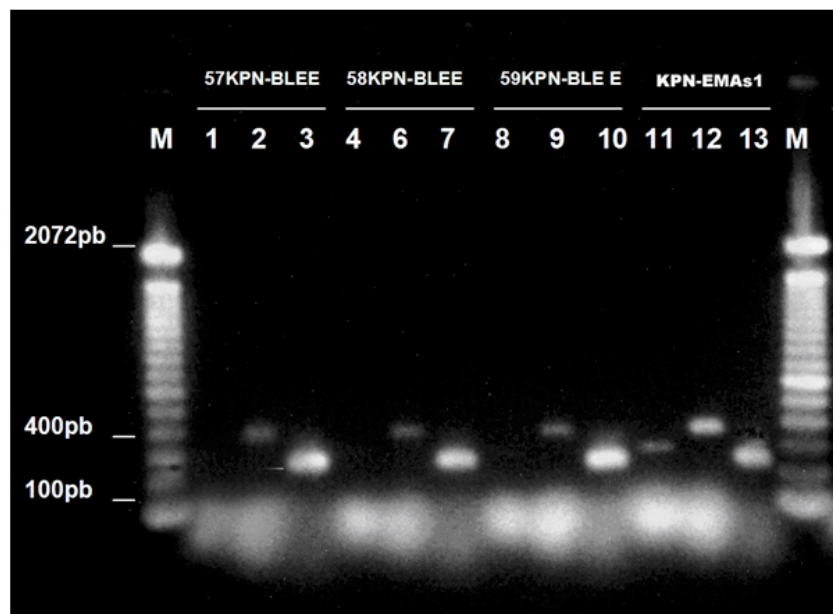

Figura 5. Gel representativo de la reacción en cadena de la polimerasa para la detección de genes productores de enzimas modificadoras de aminoglucósidos (EMAs). M - Marcador molecular; Canaletas 1, 4, 8 y 11 - Gen aac(3)-IIa; Canaletas 2-6-9-12 Gen $a a c(6)-I b$; canaletas 6, 7, 10 y 13 - Gen ant(2")-Ia. KPNBLEE, klebsiella pneumoniae productora de ß-lactamasas de espectro extendido (BLEE); KPN-EMAs1, cepa control positivo.

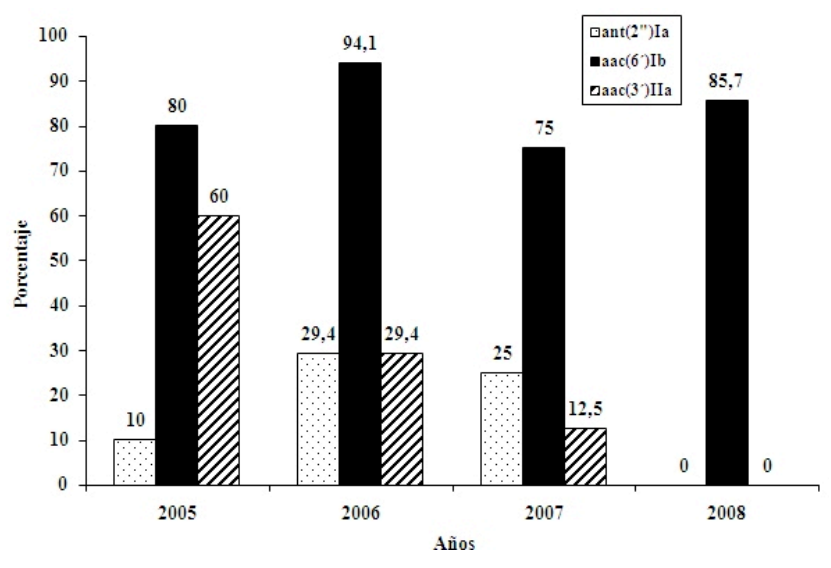

Figura 6.- Prevalencia de genes modificadores de aminoglucósidos (EMAs) en aislados clínicos de Klebsiella pneumoniae productores de $ß$-lactamasas de espectro extendido.

Los aislados correspondientes a los años 2005, 2006, 2007 y 2008 mostraron un porcentaje de resistencia a gentamicina de $60,0 \%, 52,9 \%, 50,0 \%$ y $57,1 \%$, respec- tivamente; el porcentaje de aislados resistentes a netilmicina fue $60,0 \%, 41,2 \%, 50,0 \%$ y 57,1 , en los mismos años; en el caso de tobramicina los porcentajes registrados fueron de $60,0 \%, 58,8 \%$, $50,0 \%$ y $100 \%$ y para kanamicina los aislados revelaron porcentajes de resistencia de 60,0\%, 70,6\%, $62,5 \%$ y $71,4 \%$. Por otra parte, los aislados presentaron resistencia a netilmicina en $11,8 \%$, en el año 2007, y 37,5 en el año 2008. Finalmente, se registraron porcentajes de resistencia a amikacina de $12,5 \%$ y $28,6 \%$ para los años 2007 y 2008, respectivamente (Figura 7).

En el 14,3\% de los aislados no se detectaron los genes estudiados. El 50\% de estos aislados no presentó resistencias a aminoglucósidos, 30\% registró resistencia a gentamicina, tobramicina, kanamicina y netilmicina, por último, el 10\% mostró resistencia a gentamicina y tobramicina (datos no mostrados).

\section{DISCUSIÓN}

Todos los aislados analizados mostraron resistencia a antibióti$\cos \beta$-lactámicos, perfil esperado para aislados productores de BLEE, y a uno o más antibióticos de otras familias, confirmándose la multirresistencia en este tipo de aislamientos. La resistencia simultánea a diferentes clases de antibióticos es la conse- 


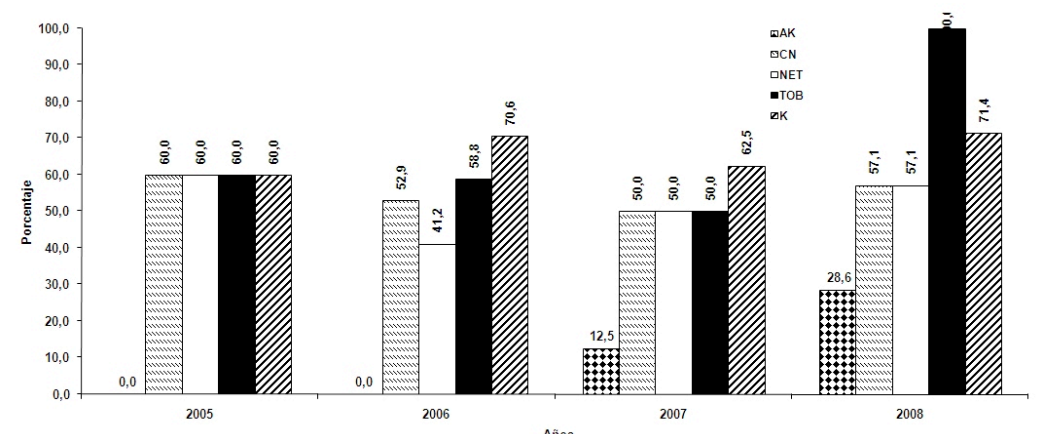

Figura 7.- Prevalencia de resistencia a antibióticos aminoglucósidos en aislados clínicos de Klebsiella pneumoniae productores de $\beta$-lactamasas de espectro extendido. AK - amikacina; CN - gentamicina; NET - netilmicina; TOB - tobramicina; K kanamicina.

cuencia fenotípica de la diseminación de genes portados por elementos genéticos transferibles y de la selección de cepas por el uso inadecuado de antibióticos (21). La multirresistencia en este estudio, mostrada en diferentes porcentajes, ha sido documentada por varios autores en trabajos anteriores $(22,23,24$ y 25$)$.

No se registraron aislados resistentes a carbapenémicos (imipenem y meropenem), lo cual concuerda con datos de publicaciones anteriores (22, 26 y 27). La actividad antibacteriana de las polimixinas (colistina y polimixina B) fue del $100 \%$, anteriormente se ha descrito el bajo porcentaje de resistencia a polimixinas (menor al 2\%) en enterobacterias (28). Tigeciclina fue efectiva contra la totalidad de los aislados, similar a porcentajes superiores al 90\% publicados previamente ( 29 y 30 ).

La capacidad de los aislados para inhibir, enzimáticamente, la acción de los aminoglucósidos se investigó determinando la presencia de genes codificadores de EMAs. En los aislados pertenecientes al año 2005, 2006 y 2007 se detectaron los genes $\operatorname{aac}(3 a)-I I a, a a c\left(6^{\prime}\right)-I b$ y $\operatorname{ant}\left(2^{\prime \prime}\right)-I a$, en estos aislados se registró resistencia a gentamicina, tobramicina, netilmicina y tobramicina, perfil de resistencia descrito para enzimas producidas por estos genes $(18,31 \mathrm{y}$ 32). Sin embargo, no se registró la resistencia a amikacina esperada por la presencia de $a a c\left(6^{\prime}\right)-I b$, además en los aislados correspondientes a los años 2006 y 2007 se observó resistencia a neomicina, lo cual pude deberse a genes no incluidos en el estudio.

En los aislados obtenidos en el año 2008 se detectó únicamente el gen $a a c\left(6^{\prime}\right)-I b$ y se observó resistencia a amikacina, gentamicina, tobramicina, netilmicina y kanamicina. Datos que coinciden con lo reportado para aislados portadores de $a a c\left(6^{\prime}\right)-I b(18)$.

\section{Conclusiones:}

1.- Los aislados de Klebsiella pneumoniae productora de $\beta$-lactamasas de espectro extendido incluidos en este estudio presentan un predominio de cefotaximasas sobre las ceftazidimasas, como ya se ha registrado en América Latina.

2.- Los aislados de Klebsiella pneumoniae mostraron una alta resistencia a $\beta$-lactámicos, mientras que, no registraron resistencia a polimixina $\mathrm{B}$, colistina, tigeciclina y los carbapenemes. A pesar 
de que en otros países ya se han registrado cepas resistentes a estos antimicrobianos.

3. Los aislados de Klebsiella pneumoniae registraron un porcentaje variado de resistencia a aminoglucósidos con resistencia baja a la amikacina y resistencia alta a gentamicina y tobramicina.

4.- Los genes EMAs se encuentra en alta proporción en los aislamientos KPN productores BLEE, principalmente el gen $\operatorname{aac}\left(6^{\prime}\right)-$ IIa, seguido de $\operatorname{ant}\left(2^{\prime}\right)$-Ia y $\operatorname{aac}(3)$ IIa.

5.- Los genes codificadores de enzimas modificadoras de aminoglucósidos presentes en los aislados de Klebsiella pneumoniae variaron según el año de estudio. El gen aac(6')-IIa fue el más prevalente, aumentando su porcentaje desde el año 2005 al 2008.

\section{REFERENCIAS BIBLIOGRÁFICAS:}

1 GARCIA DE LA TORRE, M.; ROMEROVIVAS, J.; MARTINEZ-BELTRÁN, J.; GUERRERO, A.; MESEGUER, M. \& BOUZA, E. 1985. Klebsiella bacteremia: An analysis of 100 episodes. Rev Infect Dis. 7: 143-150.

2 BISHARA, J.; LEIBOVICI, L.; HUMINER, DRUKER, M.; SAMRA, Z.; KONISBERGER, H. \& PITLIK, S. 1997. Fiveyear prospective study of bacteraemic urinary tract infection in a single institution. Eur J Clin Microbiol Infect Dis. 16: 563567.

3 CARPENTER J. L. 1990. Klebsiella pulmonary infections: Occurrence at one medical center and review. Rev Infect Dis. 12: 672-682.
4 MANDELL, BENNETT, \& DOLIN. 2005. Principles and Practice of Infectious Diseases, 6th ed. The specific pathogens. 2: 2578-2579.

5 HAEGGMAN, S.; LOFDAHL, S. \& BURMAN, L. G. 1997. An allelic variant of the chromosomal gene for class A beta-lactamase K2, specific for Klebsiella pneumoni$a e$, is the ancestor of SHV-1. Antimicrob Agents Chemother 41: 2705-2709.

6 BURWEWN, D. R.; BANERJEE, S. N.; GAYNES, R. P. 1994. Ceftazidime resistance among selected nosocomial gram-negative bacilli in the United States. J Infect Dis. 170: 1622-1625.

7 BJORN, A.; ESPEDITO, Lee C. T. \& IREDELL, J. R. 2007. Metallo $\beta$-Lactamase or Extended-Spectrum $\beta$-Lactamase: a Wolf in Sheep's Clothing. Journal of Clinical Microbiology 45: 2034-2036.

8 PATERSON, D. L. \& BONOMO, R. A. 2005. Extended-spectrum $\beta$-lactamases: a clinical update. Clin. Microbiol. 18: 657-686.

9 GISKE, C. G.; MONNET, D. L.; CARS, O. \& YEHUDA, C. 2008. Behalf of ReAct-Action on Antibiotic Resistance Clinical and Economic Impact of Common Multidrug-Resistant Gram-Negative Bacilli. Antimicrobial Agents and Chemotherapy. 52(3): 813-821.

10 GALES, A. C.; JONES, R. N. \& SANDER, H. S. 2006. Global assessment of the antimicrobial activity of polymyxin B against 54731 clinical isolates of gramnegative bacilli: report from the SENTRY antimicrobial surveillance programme (2001-2004). Clin. Microbiol. Infect. 12: 315-321.

11 GALES, A. C.; SANDER, H. S. \& JONES, R. N. 2002. Urinary tract infectiontrends in Latin American hospitals: report from the SENTRY antimicrobial surveillance program (1997-2000). Diagn. Microbiol. Infect. Dis. 44: 289-299.

12 KOSTMAN, J. R.; EDLID, T. D.; 
LIPUMA, J. J. \& STULL, T. L. 1992. Molecular Epidemiology of Pseudomonas cepacia Determined by Polymerase Chain Reaction Ribotyping. Journal of Clinical Microbiology 30 (8): 2084-2087.

13 LOPES, A.; RODRIGUES, J.; MAYSA, C.; MIRANDA, C.; NASCIMENTO, A. \& MORAIS, M. 2007. Application of PCR ribotyping and tDNA-PCR for Klebsiella pneumoniae identification. Instituto Oswaldo Cruz 102 (7): 827-832.

14 BAUER, A. W.; KIRBY, W. N. W.; SHERRINS, G. J. \& TURCK, M. 1966. Antibiotic susceptibility testing by standardized single disk method. American Journal of Clinical Pathology 45: 493-496.

15 Clinical and laboratory Standards Institute Performance standards for antimicrobial susceptibility testing; fifteenth informational supplement Sixteenth International Supplement. CLSI document. 2008. Clinical and Laboratory Standards Institute, Wayne, Pennsylvania, USA.

16 PATERSON, D. \& BONOMO, R. 2005. Extended-Spectrum $\beta$-Lactamases: a Clinical Update. Clinical Microbiology Reviews 18(4): 657-686.

17 VAKULENKO, S. \& MOBASHERY, S. 2003. Versatility of aminoglycosides and prospects for their future. Clin Microbiol Rev 16: 430-50.

18 DÍAZ, P.; BELLO, H.; DOMÍNGUEZ, M.; TRABAL, N.; MELLA, S.; ZEMELMAN, R. \& GONZÁLEZ, G. 2004. Resistencia a gentamicina, amikacina y ciprofloxacina en cepas hospitalarias de Klebsiella pneumoniae subespecie pneumoniae productoras de B-lactamasas de espectro extendido Rev Méd Chile 132: 1173-1178.

19 SENDA, K.; ARAKAWA, Y.; ICHIYAMA, S.; NAKASHIMA, K.; ITO, H.; OSHUKA, S. SHIMOKATA, K.; KATO, K. \& OHTA, M 1996. PCR detection of metallo- $\beta$-lactamase gene (blaIMP) in Gram-negative rods resistant to broad-spectrum $\beta$-lactams. Journal of Clinical Microbiology 34: 29092913.

20 MELANO, R.; CORSO, A.; PETRONI, A.; CENTRÓN, D.; ORMAN, B.; PEREYRA, A.; MORENO, N. \& GALAS, M. 2003. Multiple antibiotic-resistance mechanisms including a novel combination of extendedspectrum B-lactamases in a Klebsiella pneumoniae clinical strain isolated in Argentina. $J$ Antimicrob Chemother 52: 36-42.

21 ESPINAL, P.; MANTILLA, J.; SAAVEDRA, C.; LEAL, A.; ALPUCHE, C. \& VALENZUELA, E. 2004. Epidemiología molecular de infección nosocomial por Klebsiella pneumoniae productora de $\beta$ lactamasas de espectro extendido. Biomédica 24: 252-61.

22 AKYAR I. 2008. Antibiotic resistance rates of extended spectrum beta-lactamase producing Escherichia coli and Klebsiella spp. strains isolated from urinary tract infections in a private hospital. Mikrobiyol Bul. 42(4): 713-5.

23 FEIZABADI, M. M.; ETEMADI, G.; YADEGARINIA, D.; RAHMATI, M.; SHABANPOOR, S. \& BOKAEI, S. 2006. Antibiotic-resistance patterns and frequency of extended-spectrum beta-lactamase-producing isolates of Klebsiella pneumoniae in Tehran. Med Sci Monit. 12(11): 362-365.

24 SÁNCHEZ, J.; IGLESIAS, J.; FERNÁNDEZ, J.; PÉREZ-THEN, E.; RAMÍREZ, S.; ORTEGA, G.; JIMÉNEZ, L. 2005. Aislamiento de Klebsiella pneumoniae productora de Beta-Lactamasas de Espectro Extendido (BLEE) en recién nacidos en el Hospital Infantil Dr. Robert Reid Cabral de Santo Domingo, República Dominicana. Revista Panamericana de Infectología 7(4):15-20.

25 MARTÍNEZ, P.; ESPINAL, P.; BUSTOS, A. \& MATTAR, S. 2005. Prevalencia de 
Klebsiella pneumoniae y Escherichia coli productoras de $\beta$-lactamasas de espectro extendido (BLEE), en el Hospital San Jerónimo de Montería. MedUNAB 8(1): 15-22.

26 SEKOWSKA, A, WRÓBLEWSKA, J. \& Gospodarek, E. 2008. ESBL-positive and ESBL-negative Klebsiella pneumoniae and Klebsiella oxytoca strains occurrence in clinical specimens and susceptibility to selected antibiotics. Med Dosw Mikrobiol 60(1): 39-44.

27 KIREMITCI, A.; DINLEYICI, EC.; ERBEN, N.; DURMAZ, G.; YARGIC, Z.A.; AYBEY, A. D. \& USLUER, G. 2006. In vitro activity of ertapenem and other carbapenems against extended-spectrum betalactamase producing Escherichia coli and Klebsiella pneumoniae clinical isolates in a tertiary care center in Turkey. Expert Opin Pharmacother 9 (9): 1441-1449.

28 MOREJÓN, M. G. 2006. Variantes terapéuticas en la sepsis provocada por gérmenes multirresistentes. RevCubana Farm 40 (2).

29 MARTÍNEZ, E.; ALQUICHIRE, C.; PÉREZ, C.; PRADA, G.; ROZO, V. \& LAROTTA, J. 2007. Comparación de la actividad in vitro de la tigeciclina contra microorganismos causantes de infección en pacientes hospitalizados en Colombia: estudio de evaluación y vigilancia de tigeciclina. Asociación Colombiana de Infectología 11 (4):159-170.

30 CURCIO, D. J. \& ISTÚRIZ, R. E. 2006. Tigeciclina, la primera glicilciclina. Revista Panamericana de Infectología 8 (3): 35 42.

31 GONZÁLEZ, G.; MELLA, S.; ZEMELMAN, R.; BELLA, H. \& DOMÍNGUEZ, M. 2004. Integrones y cassettes genéticos de resistencia: estructura y rol frente a los antibacterianos. Revista médica de Chile 132: 619-626.

32 ZURITA, J.; AYABACA, J.; PAVÓN, L.; ESPINOSA, Y.; NARVÁEZ, I. \& Grupo REDNARBEC. 2001. Se detectan Enterococcus facium resistenctes a vancomicina en dos hospitales de quito. Revista electrónica de la Sociedad Ecuatoriana de Medicina Crítica, volumen 2. 